\title{
Management of pancreatic fluid collections
}

\author{
Dimpal Bhakta, Rabia de Latour, Lauren Khanna
}

New York University School of Medicine, New York, USA

Contributions: (I) Conception and design: All authors; (II) Administrative support: R de Latour, L Khanna; (III) Provision of study materials or patients: All authors; (IV) Collection and assembly of data: All authors; (V) Data analysis and interpretation: All authors; (VI) Manuscript writing: All authors; (VII) Final approval of manuscript: All authors.

Correspondence to: Lauren Khanna, MD, MS. 240 East 38th Street, Floor 23, New York, NY 10016, USA. Email: lauren.khanna@nyulangone.org.

\begin{abstract}
Pancreatic fluid collections often develop as a complication of acute pancreatitis but can be seen in a variety of conditions including chronic pancreatitis, trauma, malignancy or post-operatively. It is important to classify a pancreatic fluid collection in order to optimize treatment strategies and management. Most interventions are targeted towards the management of delayed complications of pancreatitis, including pancreatic pseudocysts and walled-off necrosis (WON), which often develop days to weeks after the initial episode of pancreatitis. Surgical, percutaneous, and endoscopic interventions are all possible methods for treatment of pancreatic fluid collections, however endoscopic drainage with endoscopic ultrasound has become first-line. Advances within endoscopic drainage strategies have also led to innovative changes in the specific stents used for treatment, with possible options including double pigtail plastic stents, fully covered self-expanding metal stents and lumen-apposing metal stents (LAMS).
\end{abstract}

Keywords: Drainage; pancreatitis; pancreatic fluid collection; stents; walled-off necrosis (WON)

Received: 04 November 2020; Accepted: 10 February 2021; Published: 25 April 2022.

doi: $10.21037 / \operatorname{tgh}-2020-06$

View this article at: http://dx.doi.org/10.21037/tgh-2020-06

\section{Introduction}

Acute pancreatitis is one of the most common diseases of the gastrointestinal tract with multiple potential complications including pancreatic fluid collections (1). Pancreatic fluid collections can also be local complications related to trauma, malignancy, or post-operative. The most common pancreatic fluid collections that require intervention or drainage include symptomatic pancreatic pseudocysts and walled-off pancreatic necrosis. Options for drainage of these collections include surgical, percutaneous, and endoscopic with the latter now becoming the preferred approach due to the advent of endoscopic ultrasound-guided drainage as well as technical advances in the various stents used for management of these pancreatic fluid collections.

\section{Classification of pancreatic and peripancreatic collections}

Acute pancreatitis is divided into two types, interstitial edematous pancreatitis, and necrotizing pancreatitis, both of which can lead to local complications including pancreatic fluid collections (2). Interstitial edematous pancreatitis accounts for $80-85 \%$ cases of acute pancreatitis while necrotizing pancreatitis accounts for $15-20 \%(3,4)$. The revised Atlanta classification is used to define the various types of pancreatic fluid collections which include acute peripancreatic fluid collection, pancreatic pseudocyst, acute necrotic collection, and walled-off necrosis (WON) (2). In the revised Atlanta classification, a distinction is made between collections that are composed of fluid only, versus those with necrosis and a solid component (but may still contain some amount of fluid). Interstitial edematous pancreatitis (Figure 1) can lead to an acute peripancreatic fluid collection (Figure 2) which is considered an early local complication (less than 4 weeks) and a pancreatic pseudocyst (Figure 3) which is considered a delayed local complication (greater than 4 weeks). Similarly, necrotizing pancreatitis (Figure 4) can lead to the development of an acute necrotic collection (seen in the early phase of disease, less than 4 weeks, 


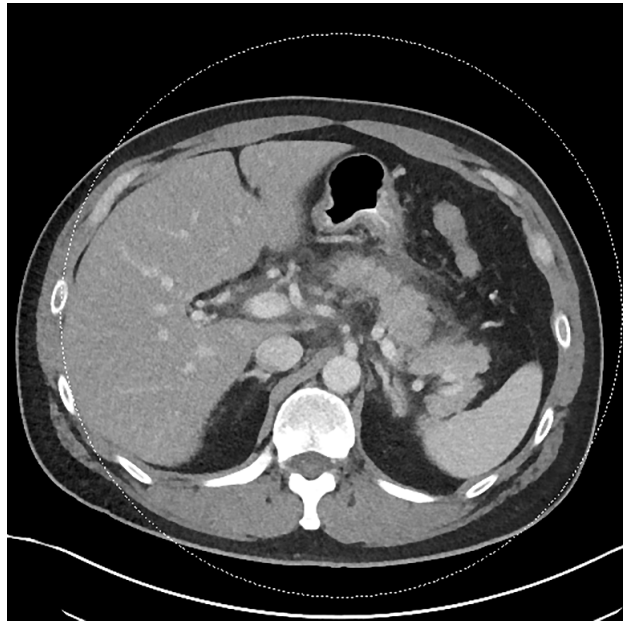

Figure 1 Acute interstitial pancreatitis.

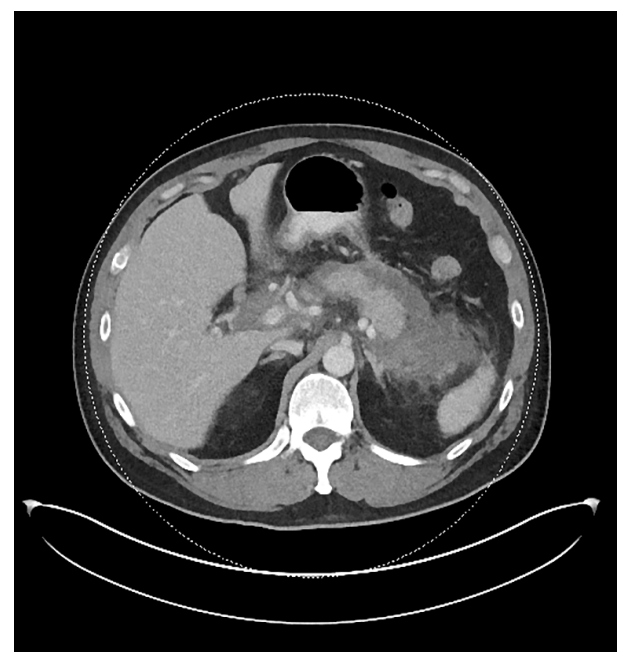

Figure 2 Acute peripancreatic fluid collection.

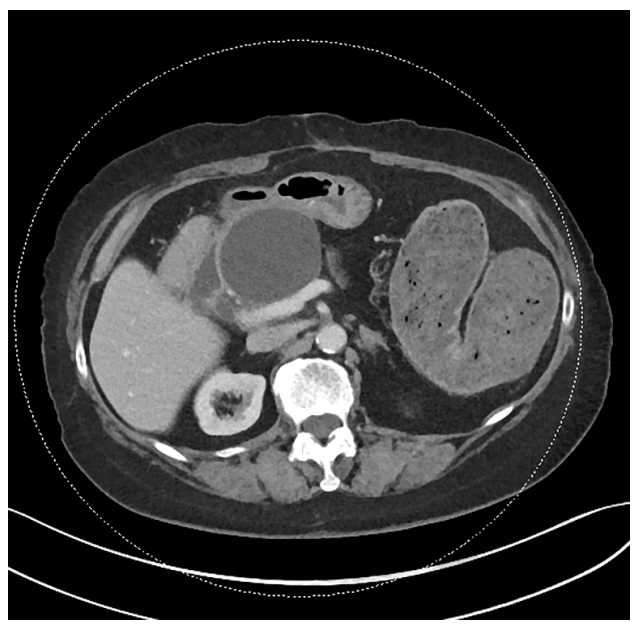

Figure 3 Pancreatic pseudocyst.
Figure 5) and WON (a mature collection seen after 4 weeks, Figure 6) (2).

The various pancreatic collections have specific morphological features as seen on contrast enhanced computed tomography. An acute peripancreatic fluid collection is homogenous and fluid-filled with no definable wall and is adjacent to the pancreas and seen within the first 4 weeks after an episode of interstitial edematous pancreatitis. A pancreatic pseudocyst, however, is a well circumscribed, fluid-filled encapsulated collection with a well-defined inflammatory wall seen after maturation which typically requires at least 4 weeks. An acute necrotic collection is heterogenous and contains variable amounts of liquid and necrosis, with no definable wall, found in the pancreatic parenchyma or the peripancreatic tissue seen within the first 4 weeks after an episode of necrotizing pancreatitis. WON is also heterogenous with variable amounts of liquid and necrosis, however has developed a well-defined wall with complete encapsulation and is seen after maturation which generally requires at least 4 weeks.

\section{Indications for drainage of pancreatic fluid collections}

The management and indications for drainage vary based on the type of pancreatic fluid collection. Acute pancreatic fluid collections remain sterile and often resolve spontaneously without intervention (5). Most other pancreatic fluid collections can also be observed. Drainage is recommended when symptoms develop, including pain or symptoms of luminal obstruction such as nausea, vomiting, early satiety, evidence of superinfection, or signs concerning for biliary obstruction such as jaundice (6). Size alone is not considered an indication for drainage but large collections are more likely to be symptomatic $(7,8)$. Options for drainage include surgical, percutaneous, and endoscopic.

\section{Surgical drainage}

Surgical drainage has long been considered an effective therapeutic modality for the management of pancreatic fluid collections. Surgical approaches include both open and laparoscopic techniques. Surgical cystgastrostomy can be performed in the setting of pancreatic pseudocysts and surgical necrosectomy for WON. Prior studies have shown overall success rates after laparoscopic, open, and endoscopic pancreatic cystgastrostomy for pancreatic 


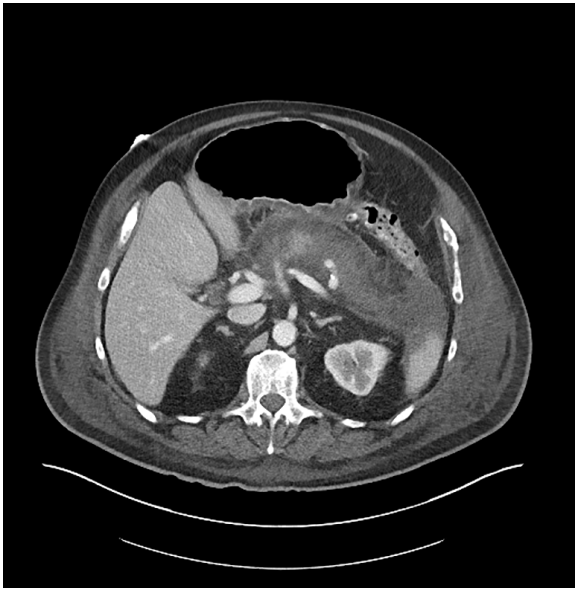

Figure 4 Acute pancreatic necrosis.

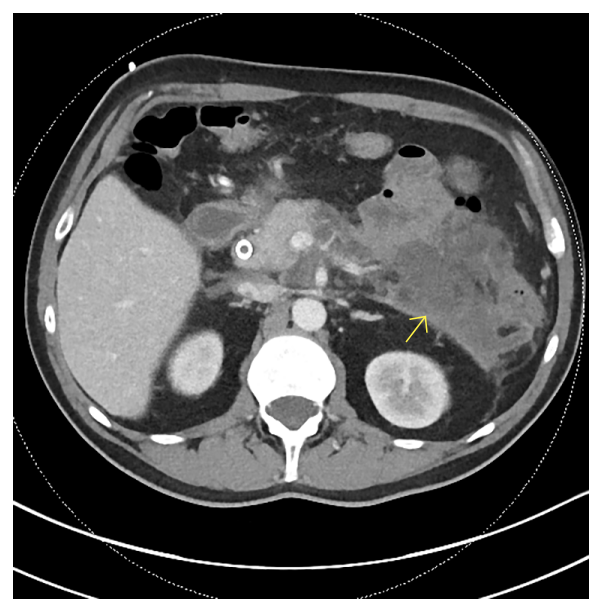

Figure 5 Acute necrotic collection.

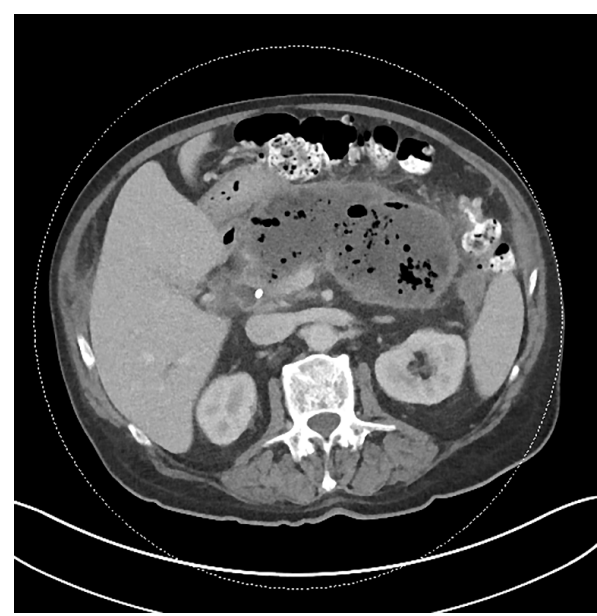

Figure 6 Walled off necrosis. pseudocysts are essentially equivalent (9). Surgical drainage is the preferred method in multi-loculated collections with several septations. A randomized control trial by Varadarajulu et al. comparing endoscopic and surgical cystgastrostomy for pancreatic pseudocyst drainage showed no differences in treatment successes between the groups, however endoscopic treatment was associated with shorter hospital stays, better physical and mental health of the patients, and lower overall cost (10). For management of infected pancreatic necrosis, van Santvoort et al. performed a randomized trial comparing a minimally invasive step approach, which included percutaneous or endoscopic drainage, to open necrosectomy and concluded that a minimally invasive step-up approach led to a decrease in rates of major complications and death (11).

\section{Percutaneous drainage}

Percutaneous drainage remains another modality for the treatment of pancreatic fluid collections. Percutaneous drainage is the placement of an external drain performed most commonly by interventional radiology under computed tomography guidance or ultrasound with fluoroscopic guidance. Studies comparing percutaneous drainage to surgical drainage have resulted in mixed outcomes. Adams et al. performed a retrospective review comparing percutaneous drainage to surgical internal drainage for the management of symptomatic pancreatic pseudocysts and noted that percutaneous drainage was associated with significantly more complications including drain track infection, however percutaneous drainage had a lower mortality rate when compared to surgical drainage (12). Alternatively, Heider et al. also performed a retrospective review comparing the effectiveness of percutaneous drainage to surgical treatment of pancreatic pseudocysts in unselected patients and found percutaneous drainage to be successful in $42 \%$ of patients, whereas surgical treatment had an $88 \%$ success rate (13). Heider et al. additionally concluded that percutaneous drainage resulted in higher mortality, morbidity and longer hospital stay compared to surgical management (13). A retrospective cohort study performed by Akshintala et al. assessed the outcomes of endoscopic versus percutaneous drainage for symptomatic pancreatic pseudocysts and concluded that although both approaches had similar clinical success rates, percutaneous drainage was associated with significantly higher rates of reintervention, longer length of hospital 
stay, and increase number of follow-up abdominal imaging studies (14). For the management of complications related to necrotizing pancreatitis including infected necrosis, studies have shown primary percutaneous catheter drainage has fewer complications than primary surgical necrosectomy (15). Percutaneous drainage for the management of infected necrosis remains an important treatment modality, especially in those patients that are critically ill and may not be candidates for endoscopic or surgical drainage. Potential complications of percutaneous drainage include drain track infections, catheter occlusion, cellulitis, and the development of a pancreatic cutaneous fistula $(16,17)$.

\section{Endoscopic drainage}

Endoscopic drainage of pancreatic fluid collections, although a relatively new modality compared to surgical and percutaneous drainage, is considered highly effective and often first line therapy for management of symptomatic pancreatic fluid collections $(18,19)$. In 1973, Rogers et al. published a case report describing endoscopic transgastric needle aspiration of a pancreatic pseudocyst, becoming the first ever described case of an endoscopic intervention for a pancreatic fluid collection (20). In 1985, Kozarek et al. published a series of endoscopic cystgastrostomy and cystenterostomy in four high risk patients with pancreatic pseudocysts (21). Initially, these earlier techniques for endoscopic drainage were performed using conventional transmural drainage (described in the following section). Endoscopic ultrasound-guided (EUS) drainage is now the preferred method due to various technical advantages, improved therapeutic accuracy and overall improved outcomes.

\section{Conventional transmural endoscopic pancreatic fluid collection drainage}

For the management of pseudocysts, there are various endoscopic approaches including transpapillary drainage, transmural drainage through the gastrointestinal wall or a combination of both (22). As previously discussed, earlier techniques for endoscopic drainage were performed using conventional transmural drainage. In all cases of transmural drainage, the creation of a connection between the gastrointestinal lumen and the collection is required, usually a cystgastrostomy or cystduodenostomy (23). The main difference between conventional transmural drainage as compared to EUSguided drainage is the initial step in which access to the pancreatic fluid collection is obtained (24). Access to the pancreatic fluid collection in the conventional approach is obtained by localization of a bulge or an endoscopically visible extrinsic luminal compression (25). However, with the advent of endoscopic ultrasound, specific advantages have been recognized including direct real time visualization of the fluid collection, avoiding the risk of inadvertently accessing an alternative structure, avoiding vasculature, the ability to evaluate the contents of the collections, and to obtain a measurement of the distance between the luminal wall and the collection (24). An EUS-guided approach allows for evaluation of the surrounding vascular structures, therefore decreasing the risk of bleeding secondary to puncturing through a vessel, and allows for drainage of collections that do not produce a bulge or extrinsic luminal compression (24). Park et al. performed a prospective randomized controlled trial comparing EUS-guided versus conventional transmural drainage of pancreatic pseudocysts and found that the technical success rate was higher for EUS-guided drainage (26). Similarly, Varadarajulu et al. performed a prospective randomized control trial comparing EUSguided to EGD-guided transmural drainage of pancreatic pseudocysts and noted a $100 \%$ success rate in patients undergoing EUS-guided drainage compared to $33 \%$ in those randomized to EGD-guided drainage $(\mathrm{P}<0.001)$ but further noted the increased risk of major procedurerelated bleeding in patients whom drainage by EGD was attempted (27).

\section{Endoscopic ultrasound-guided pancreatic fluid collection drainage}

In 1992, Grimm et al. reported the first case of a pseudocyst puncture under direct endoscopic ultrasound guidance using an oblique echoendoscope followed by use of a duodenoscope for placement of an endoprosthesis (28). In 1996, Wiersema et al. reported a case of pseudocyst drainage performed using a prototype linear therapeutic echoendoscope allowing the entire procedure to be completed with one instrument (29). This was then followed by Vilmann et al. describing the first case of a onestep EUS-guided pseudocyst drainage and deployment of a stent through the echoendoscope in 1998 (30).

The overall approach to EUS-guided transmural pancreatic fluid collection drainage begins with localization 


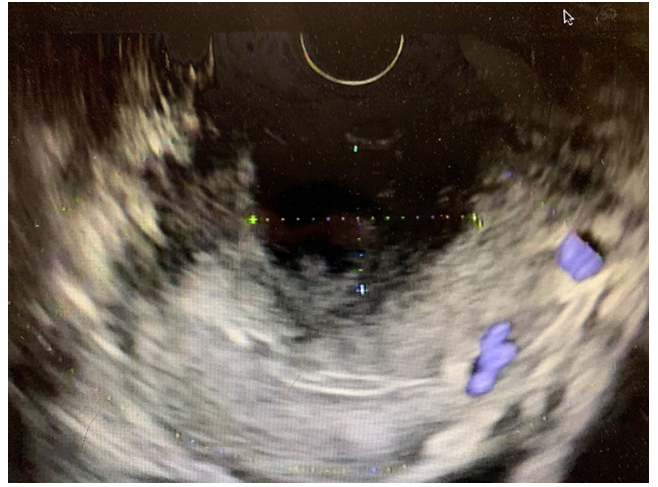

Figure 7 EUS view: PFC. EUS, endoscopic ultrasound; PFC, pancreatic fluid collection.

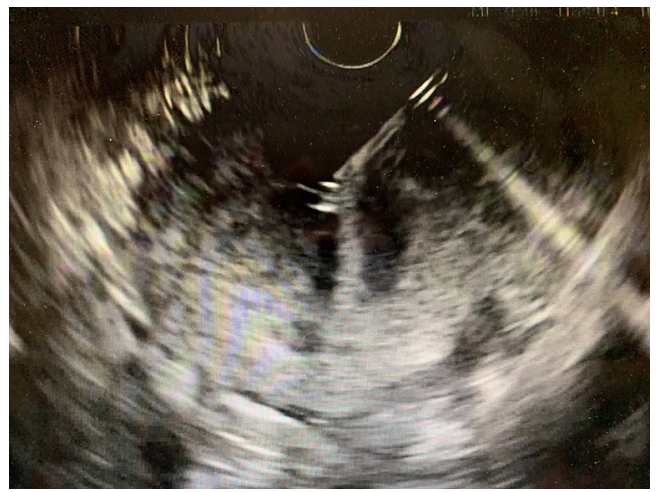

Figure 8 EUS view: insertion of 19-gauge needle into PFC. EUS, endoscopic ultrasound; PFC, pancreatic fluid collection.

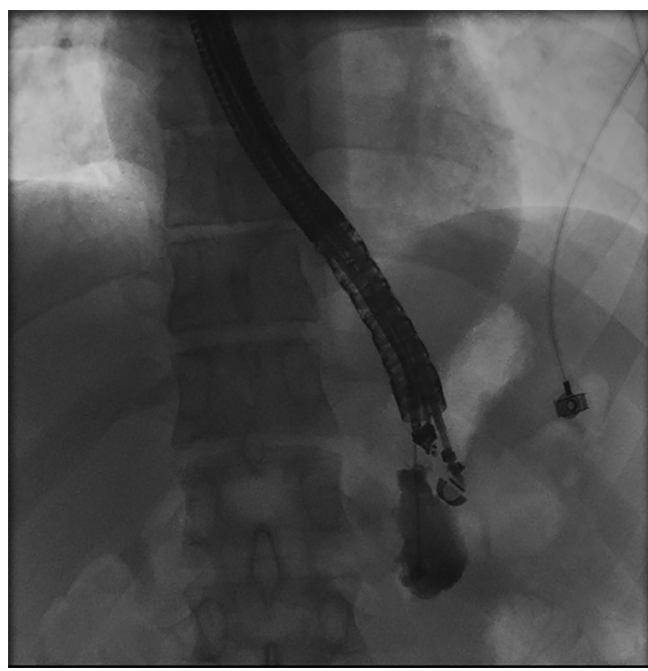

Figure 9 Fluoroscopy view: contrast injection into cavity of PFC. $\mathrm{PFC}$, pancreatic fluid collection.

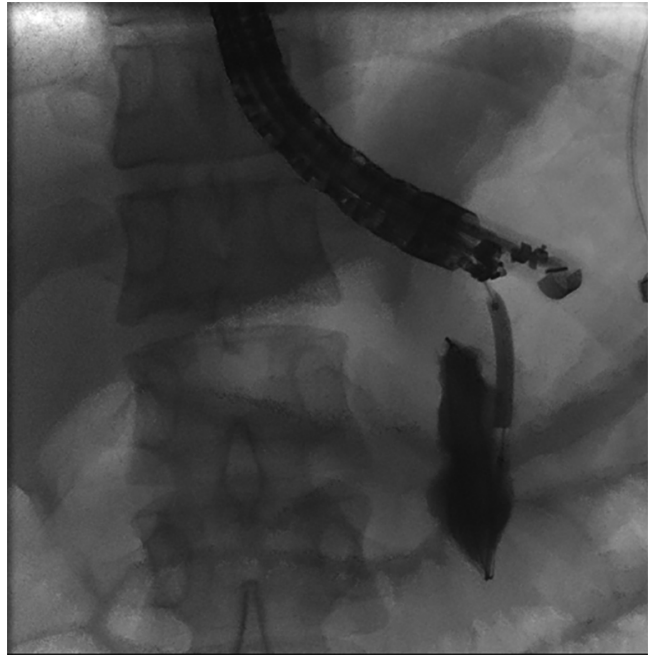

Figure 10 Fluoroscopy view: balloon dilation of gastric wall tract into PFC. PFC, pancreatic fluid collection.

and examination of the fluid collection. Features that correlate with endoscopic success include suitable anatomical location adjacent to the luminal gastrointestinal tract, size of collection $>5 \mathrm{~cm}$, gut compression with close apposition to the gastrointestinal wall $(<1 \mathrm{~cm})$, single cyst, mature cyst and absence of disconnected segment of pancreatic duct (31) (Figure 7). For drainage of pseudocysts, once ultrasound evaluation of the collection has been performed, a 19-gauge EUS needle is used to puncture the cyst wall under continuous direct EUS guidance with careful avoidance of any intervening vessels (32) (Figure 8). Contrast is injected to assess the cavity under fluoroscopic guidance (Figure 9). This is then followed by the introduction of a long guidewire through the needle and into the cyst cavity usually under fluoroscopic guidance (32). Once a tract has been created, dilation is performed either with electrocautery using a needle-knife sphincterotome or mechanically using dilating catheters or balloon dilation (33) (Figures 10,11). The final step of the procedure involves the placement or deployment of a stent (Figures 12,13). Stent type can vary and current therapeutic options include 7 French or 10 French double pigtail plastic stents, a fully covered self-expanding metal stent (FCSEMS), or a lumenapposing metal stent (LAMS).

\section{Pancreatic fluid collection drainage with fully covered self-expanding metal stents}

When using a FCSEMS for the drainage of a pancreatic 


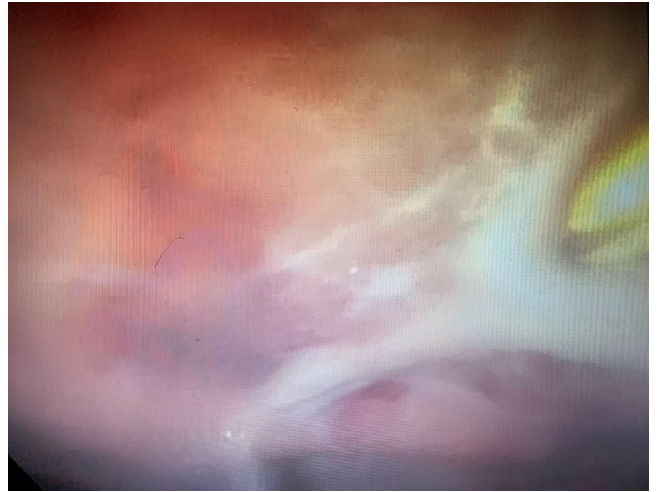

Figure 11 Endoscopy view: pus drainage after tract dilation.

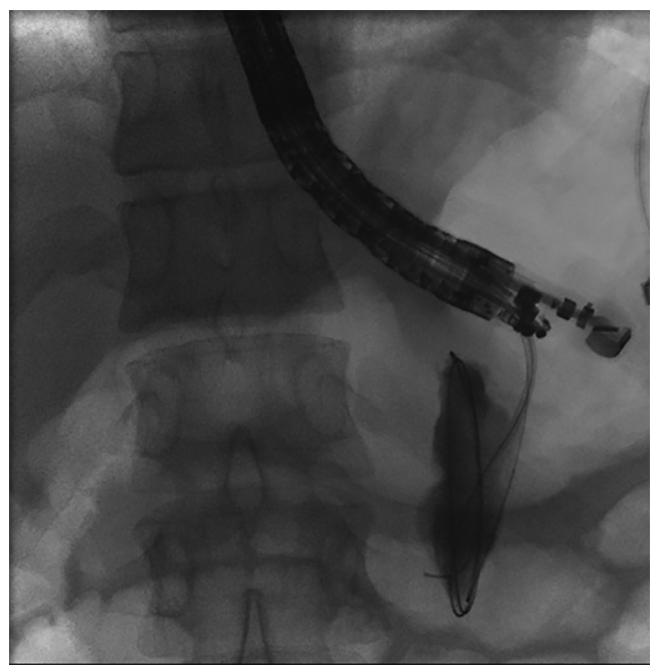

Figure 12 Fluoroscopy view: plastic stent advanced over wire coiled in PFC. PFC, pancreatic fluid collection.

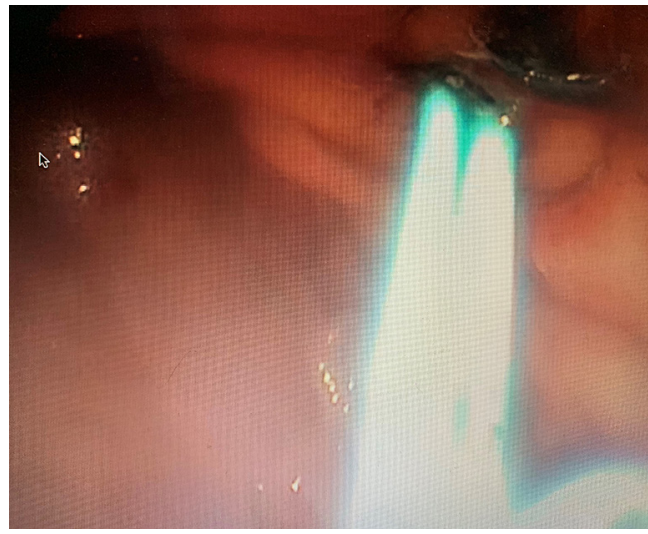

Figure 13 Endoscopy view: two double pigtail plastic stents. fluid collection, the conventional EUS-guided technique is still utilized. FCSEMS are larger in diameter than plastic stents which allows for improved drainage and decreases risk of stent occlusion. Use of FCSEMS may also reduce the need for placement of multiple plastic stents, which requires repetitive wire access of the fluid collection (34). A retrospective cohort study by Sharaiha et al. looked at 230 patients with pancreatic pseudocysts who underwent transgastric or transduodenal drainage using FCSEMS versus double pigtail plastic stents and concluded that FCSEMS placement was associated with better clinical outcomes and lower adverse event rates, including risk of stent occlusion, stent migration and infection (34). Furthermore, Yoon et al. published a metaanalysis including seven studies comparing metal stents versus plastic stents for the drainage of pancreatic fluid collections and concluded that metal stents were superior to plastic stents due to a higher clinical success rate and a lower adverse event rate (35). Yoon et al. also performed a sub-group analysis noting metal stents had a higher clinical success rate when compared to plastic stents for both pseudocysts and WON (35).

\section{Pancreatic fluid collection drainage with LAMS}

LAMS are a novel device used to accomplish endoscopic transluminal drainage by essentially forming a conduit between adjacent but not necessarily adherent lumens in the gastrointestinal tract (36). The stent has a barbell or dumbbell shape with two large flanges intended to decrease the risk of stent migration, which was a concern with FCSEMS (37). LAMS have now been designed with electrocautery-enhanced delivery and are available in a variety of diameters. After identification of an appropriate window without intervening vessels on Doppler (Figure 14), the electrocautery-enhanced catheter is advanced into the pancreatic fluid collection (Figure 15), and the stent flanges are deployed, first within the fluid collection (Figure 16) and then subsequently within the gastric or duodenal lumen (Figure 17). Adjunctive techniques include balloon dilation of the LAMS or double pigtail plastic stent placement within the LAMS (Figure 18). Siddiqui et al. conducted a multicenter, retrospective study of 82 patients with symptomatic pancreatic fluid collections who underwent EUS-guided drainage with LAMS and reported that $97.5 \%$ of stents were successfully placed with stent patency of $98.7 \%$ (38). Furthermore, LAMS were highly effective in the drainage of pancreatic 


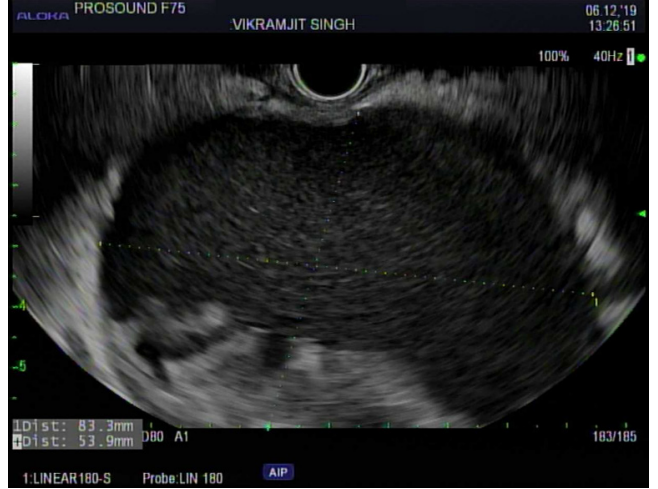

Figure 14 EUS view: PFC. EUS, endoscopic ultrasound; PFC, pancreatic fluid collection.

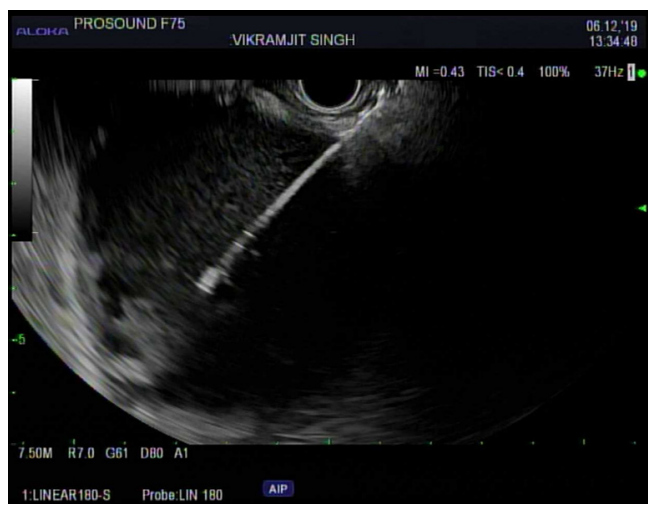

Figure 15 EUS view: PFC puncture. EUS, endoscopic ultrasound; PFC, pancreatic fluid collection.

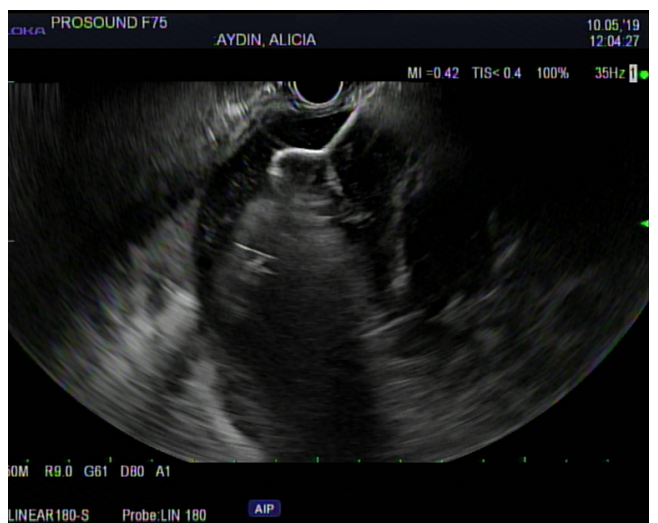

Figure 16 EUS view: deployment of LAMS flange within PFC. EUS, endoscopic ultrasound; LAMS, lumen-apposing metal stents; PFC, pancreatic fluid collection.

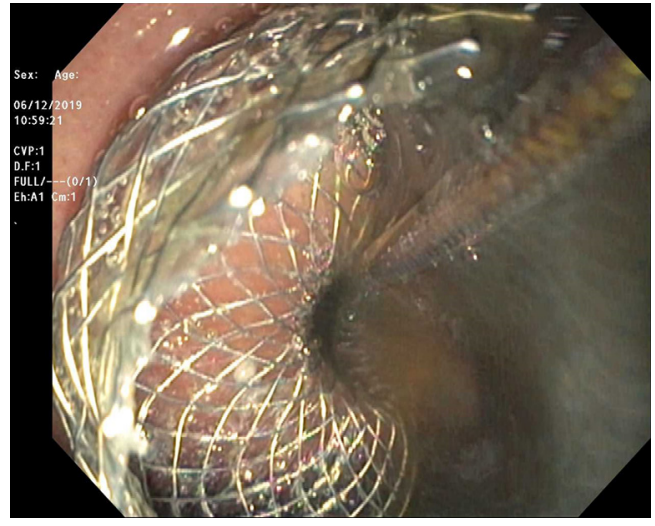

Figure 17 Endoscopic view: fluid emanating from cyst after deployment of LAMS flange in gastric lumen. LAMS, lumenapposing metal stents.

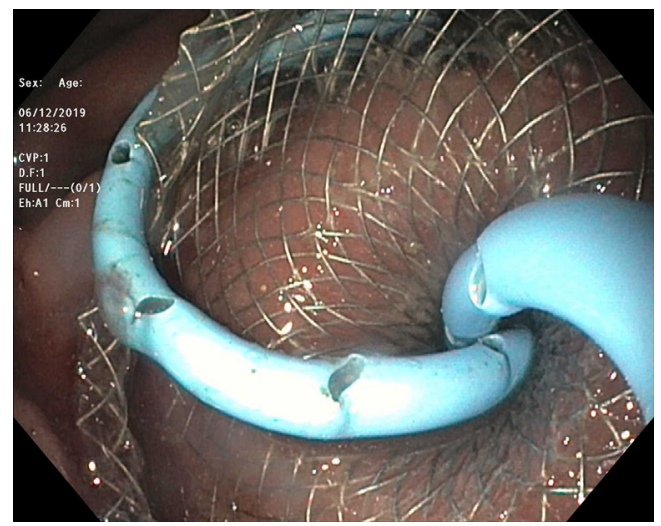

Figure 18 Endoscopic view: two double pigtail plastic stents through LAMS. LAMS, lumen-apposing metal stents.

pseudocysts with $100 \%$ success rate and $88 \%$ success rate for endoscopic decompression of WON (38). Similarly, Kumta et al. published an international, multicenter experience using LAMS for EUS-guided drainage of pancreatic fluid collections with a study of 192 patients with a technical success rate, defined as successful LAMS deployment, of $98.4 \%$ and clinical success rate, defined as resolution of fluid collection at three-month follow up, of $92.6 \%$ with low rates of adverse events (39). There are certain advantages of LAMS when compared to other stents used in the management of pancreatic fluid collections including single-step deployment, minimal stent migration and the increased ability to perform endoscopic 
debridement of the collection (40). There has been, however, recently published data raising concerns about the safety of LAMS. Lang et al. performed a retrospective analysis of 103 patients undergoing EUS-guided drainage of a pancreatic fluid collection and compared the overall efficacy and adverse event rates between double pigtail plastic stents and LAMS (41). The technical success rate was $96 \%$ with plastic stents and $94 \%$ with LAMS however adverse events including unplanned endoscopy and bleeding was $12 \%$ with plastic stents compared to $53 \%$ with LAMS $(\mathrm{P}=0.0003)$. It is important to note, however, that the number of patients in the plastic stent group was 84 while the LAMS group was 19 which may have drastically limited statistical comparison between groups.

\section{Management of pancreatic WON}

As previously discussed, WON is a mature pancreatic collection with complete encapsulation that contains variable amounts of both liquid and solid necrotic components. Endoscopic drainage of WON, when compared to that of pancreatic pseudocysts, was first described in 2007 by Papachristou et al. in which a series of 53 patients from 1998 to 2006 underwent endoscopic drainage and debridement of WON using double pigtail stents that resulted in an $81 \%$ clinical success rate with a median number of 3 endoscopic sessions per patient. However, a significant number of patients also required further percutaneous or surgical intervention (42). As previously discussed, FCSEMS have been used in the management and drainage of pancreatic fluid collections, but have a risk of stent migration. With the advent of LAMS, direct endoscopic debridement of WON after stent deployment is possible given that an endoscope can be passed into the collection through the stent lumen with lower likelihood of stent migration. Siddiqui et al. performed a retrospective cohort study comparing clinical outcomes of 313 patients undergoing EUS-guided debridement of WON with double pigtail stents, FCSEMS and LAMS and concluded there was no statistically significant difference in technical success rates in accessing WON between the double pigtail stent, FCSEMS and LAMS groups (99.1\% vs. 100\% vs. 97.7\%). However complete resolution of the WON using double pigtail stents was significantly lower than with FCSEMS and LAMS (81\% vs. 95\% vs. 90\%) (43). Furthermore, the patients that underwent WON drainage with a LAMS required a significantly lower number of repeat procedures as compared with the FCSEMS and double pigtail stent groups (43). Sharaiha et al. published similar retrospective data involving 124 patients undergoing EUS-guided drainage of WON using LAMS with technical success of $100 \%$ and clinical success of $86.3 \%$ after three months of follow-up (44). Sharaiha et al. further noted an overall stent migration rate of $5.6 \%$ in patients undergoing direct endoscopic necrosectomy with LAMS, which was markedly lower when compared with other stent types (44).

\section{Adjunctive techniques for endoscopic management of WON}

Management of WON remains challenging and often requires direct endoscopic debridement. Many adjunctive techniques have been utilized to facilitate successful debridement of necrotic tissue.

Antibiotics play a critical role in the management of infected WON although the routine use of prophylactic antibiotics to prevent infection of sterile necrosis has not been shown to be effective (45). Recent guidelines for the management of pancreatic necrosis recommends the use of broad-spectrum antibiotics such as carbapenems, quinolones, and metronidazole when there is cultureproven infection of pancreatic necrosis or when infection is strongly suspected (17). Antibiotic lavage of pancreatic necrosis has also been considered but there is no significant clinical data is currently present to warrant its clinical use. The duration of antibiotic therapy after endoscopic drainage of WON remains unclear however studies have shown longer duration of antibiotics is associated with increased risk of Clostridium difficile colitis $(46,47)$.

Discontinuation of proton pump inhibitors (PPI), when no strong indication for continuation is present, has been another suggested adjunctive technique as it is thought that gastric acid plays an important role in chemical debridement of necrotic tissue by facilitating liquefication of necrosis and preventing bacterial overgrowth (48). A recent multicenter, retrospective study by Powers et al. of patients with WON who underwent drainage with LAMS were divided into two groups, those that used PPI continuously and those that did not have continuous PPI usage during the interval of therapy, and found that there was a significant difference in the required number of direct endoscopic necrosectomies in order to achieve clinical success in the PPI $v s$. non-PPI group (3.2 vs. 4.6 respectively, $\mathrm{P}<0.01)(49)$.

Another reported innovation to improve chemical debridement of necrosis is the use of diluted hydrogen peroxide. Hydrogen peroxide has been used in other clinical 


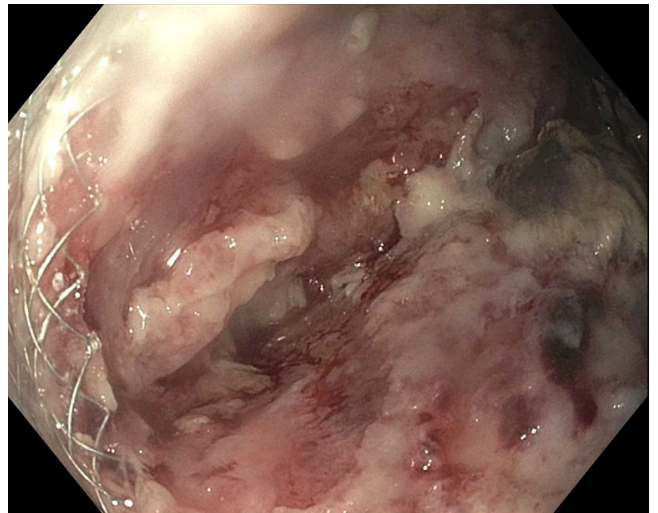

Figure 19 Endoscopic view: necrotic cavity before diluted hydrogen peroxide lavage.

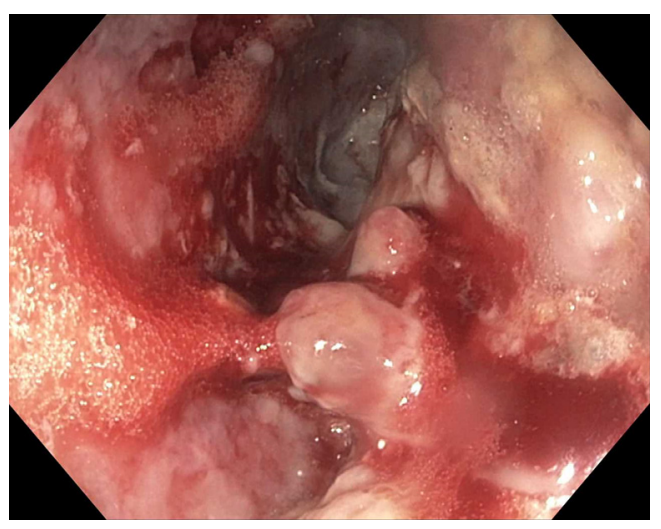

Figure 20 Endoscopic view: necrotic cavity after diluted hydrogen peroxide lavage.

contexts such as treatment of abrasions, superficial wounds, and abscesses. Hydrogen peroxide is broken down into water and oxygen by an enzyme known as catalase. When combined with organic tissue, this reaction can lead to the breakdown of necrotic debris. Diluted hydrogen peroxide can be infused into the necrotic cavity and then flushed out (Figures 19,20). At current, there is limited data to support the routine use of diluted hydrogen peroxide however case series have suggested the use of hydrogen peroxide was associated with a reduction in the number of procedures needed for endoscopic mechanical debridement $(50,51)$. It is important to note, however, that the use of hydrogen peroxide when injected into enclosed body cavities has been known to provoke, although rare, fatal to near fatal gas embolisms (52,53).

The use of indwelling nasocystic tubes for irrigation of
WON has also been reported. Nasocystic irrigation permits continuous lavage of the WON cavity and was traditionally pursued with saline and is now also utilized with hydrogen peroxide. Although limited data is available, the use of nasocystic tubes in the setting of solid debris within a collection has been associated with greater short term and long-term success when compared to drainage by stents alone as well as decreased rates of stent occlusion (54).

Direct endoscopic necrosectomy (DEN) is another adjunctive technique used for the management of WON. DEN is mechanical debridement performed by passing an endoscope directly into the cavity to facilitate the removal of necrotic debris. DEN may be necessary in collections with large amounts of solid debris and in those that fail drainage with stent placement alone (55). A "step up approach" can be utilized in that DEN is performed only after standard drainage with stents alone or after adjunctive irrigation techniques fail to completely resolve the necrotic collection (56). However, a recent retrospective study by Yan et al. looked at performing DEN for the management of WON at the time of LAMS placement as compared to delayed DEN one week later and found the clinical success rate for resolution of WON in the immediate DEN group was $91.3 \%$ compared to $86.1 \%$ in the delayed DEN group $(\mathrm{P}=0.3)$ and the mean number of necrosectomy sessions was significantly lower in the immediate DEN group as compared to the delayed DEN group (3.1 vs. 3.9, $\mathrm{P}<0.001$ ) (57). DEN is generally safe but may be associated with adverse events including air embolism, bleeding and perforation; thus, the decision to perform DEN should be made on a case-by-case basis and at a high volume center (17).

Two additional techniques that have been used for the management of WON include dual modality drainage (DMD) and multiple transluminal gateway technique (MTGT). DMD was first described by Ross et al. in 2010 whereby endoscopic transmural drainage was performed immediately after percutaneous drainage (58). A prospective study by Ross et al. reviewed long terms outcomes of 117 patients who had undergone DMD for the management of WON and found that no patients required surgical necrosectomy, there were no procedure-related deaths and no patient developed a pancreatic cutaneous fistula (59). MTGT was first described by Varadarajulu et al. in 2011 in which multiple transmural tracts are created under EUS guidance in order to facilitate drainage (60). When first described, a combination of nasocystic irrigation and placement of double pigtail placement stents was used. Now with the advent of LAMS, this technique is not as 
frequently utilized but MTGT could be considered if LAMS with DEN fails (55).

\section{Cost effectiveness of LAMS}

Although the use of LAMS for the management of pancreatic fluid collections has increased, it is important to note the costs associated with these newer devices. A costeffectiveness analysis performed by Chen et al. compared plastic stents to LAMS for the endoscopic drainage of pseudocysts. According to their study, the use of LAMS cost on average $\$ 17,024$ per patient compared to $\$ 10,087$ for plastic stents with a success rate of $93.9 \%$ for LAMS and $97.0 \%$ for plastic stents suggesting the use of plastic stents should be preferred over LAMS for the initial endoscopic management of pseudocysts (61). In a costeffective analysis comparing LAMS to plastic stents for the management of WON, however, Chen et al. concluded that although the use of LAMS was more costly at \$20,029 per patient, compared to $\$ 15,941$ for plastic stents per patient, the increased effectiveness for WON may favor its use over plastic stents (LAMS $92.2 \%$ effective versus plastic stents $83.9 \%$ effective) (62). Furthermore, the rates of unplanned endoscopy and surgical intervention were both lower with the use of LAMS. The difference in outcomes for the management of pseudocysts versus WON are likely secondary to the favorable stent characteristics of LAMS including their large diameter making obstruction from solid debris more commonly seen in WON less likely and the ability to perform DEN through the stent.

\section{Disconnected pancreatic duct syndrome (DPDS)}

DPDS occurs when there is a complete transection of the pancreatic duct resulting in a severe pancreatic leak. DPDS is often secondary to necrotizing pancreatitis but it can also be seen secondary to trauma, post-operative complication, chronic pancreatitis, and malignancy (63). Clinically features concerning for a pancreatic duct leak including the development or recurrence of a pancreatic fluid collection, however the diagnosis and management remains challenging. Current proposed criteria for the diagnosis of DPDS includes the presence of necrosis of at least $2 \mathrm{~cm}$ of pancreas on CT or MR imaging, viable pancreatic tissue upstream or toward the pancreatic tail, and extravasation of contrast material injected into the main pancreatic duct at pancreatography (64). Definitive treatment of DPDS is operative resection of the disconnected segment but this is associated with high periprocedural morbidity (17). Less invasive approaches to the management of DPDC include percutaneous, endoscopic or minimally-invasive surgical techniques. Endoscopic management may include transpapillary drainage via endoscopic retrograde cholangiopancreatography (ERCP) with stent placement, transmural drainage via EUS-guided stent placement, or a combination of transpapillary and transmural stenting $(65,66)$. The goal of transpapillary stenting is to alter the pressure gradient and allow for favored transpapillary drainage from the pancreas proximal to the damaged duct. Complete bridging of the transected duct is ideal although technically challenging and thus placement of a transpapillary stent up to the fluid collection is recommended in most cases. The transpapillary drain is typically removed within a 4-week period. The optimal timing of transmural stent placement remains unclear as early stent removal is associated with recurrence of pancreatic leak; however long-term placement of stents may be complicated by stent occlusion, migration, or infection. Permanent transmural stenting may be considered to decrease the risk of recurrence by creating a permanent fistula between the main pancreatic duct and the gastrointestinal lumen (67).

\section{Disadvantages and complications of endoscopic drainage}

Although endoscopic interventions remain a successful minimally invasive approach to the management and drainage of pancreatic fluid collections, there are disadvantages and complications that should be considered. With the advent of EUS-guided drainage and the ability to perform the procedure with further imaging guidance, there has been decreased risk of complications given that local structures that could be confused for fluid collections and vasculature can be visualized in real time (68). Furthermore, the technical success rate of EUS-guided transmural drainage of pancreatic fluid collections has been reported to be greater than $90 \%$ (19). Disadvantages to EUS-guided drainage include a recognized learning curve given the procedure can be highly technical, especially in light of newer technologies. Procedure times may be lengthy and many patients may require multiple procedures. Increased provider experience and different stent qualities have shown to be associated with significantly improved success rates and decreased rate of complications (69). Complications associated with EUS- 
guided drainage of pancreatic fluid collections include bleeding, perforation, infection and stent specific complications, including migration and occlusion (70).

Bleeding related to endoscopic drainage can be further subdivided into early and delayed bleeding. Again, one of the advantages of EUS-guidance is to help reduce the risk of bleeding, particularly early bleeding, by visualizing any intervening vessels. Bleeding during the procedure can occur at the site of puncture, even with ultrasound guidance and avoidance of intervening vessels, or from within the cavity (71). Bleeding can also be seen in the setting of pseudoaneurysm development due to stent-induced arterial injury, which often presents after rapid decompression of the pancreatic collection (70). In various published studies, the risk of bleeding varies with a range of $1-10 \%$ (70). In a retrospective study of 149 patients by Brimhall et al. undergoing endoscopic drainage of pseudocysts and WON, LAMS when compared to double pigtail stents had a higher risk of pseudoaneurysm bleeding (OR 10.0, 95\% CI: $1.2-$ 84.6, $\mathrm{P}=0.009$ ) (72). In the case of uncontrolled bleeding or presumed pseudoaneurysm bleeding, angiography and embolization by interventional radiology may be required and should be pursued early; in rare cases, surgical exploration may be required (71).

The incidence of perforation during EUS-guided drainage of pancreatic fluid collections varies from $0-4 \%(70)$. In a prospective review performed by Varadarajulu et al. of 148 patients undergoing EUSguided drainage of pancreatic fluid collections, perforation occurred in two patients $(1.3 \%)$ who had attempted transgastric pseudocyst drainage in the uncinate region (73). The authors noted when compared to other locations, perforation was more common when the fluid collection involved the uncinate process making location of the attempted drainage a possible risk factor $(0 \%$ vs. $50 \%$, $\mathrm{P}=0.0005)$ (73).

Another well recognized complication of endoscopic drainage of pancreatic fluid collections is infection. Infection is most commonly secondary and occurs in the setting of blocked or occluded stents leading to incomplete drainage or entry into and contamination of a previously sterile pancreatic fluid collection. The incidence varies but has reported to range between $0-10 \%$ (70). Recent literature has suggested that the addition of double pigtail stents through a LAMS as opposed to LAMS alone for the management of pancreatic pseudocysts is associated with decreased risk of infection requiring reintervention (17\% in LAMS only group compared to $0 \%$ in the double pigtail stent plus LAMS group, $\mathrm{P}=0.054)$ (74).

Stent specific complications include stent migration, stent occlusion and buried stents. Stent migration, as previously mentioned, is a known complication when using plastic stents and FCSEMS and has been reported to range between $1-15 \%$ (75). Often migration of the stent at time of final deployment can be mitigated by gradual withdrawal and torquing of the echo-endoscope (71). Stent occlusion is a common culprit in causing secondary infection but can be managed by additional endoscopic debridement, especially in the setting of occlusion secondary to solid necrosis. In the setting of occlusion of a LAMS, the placement of additional plastic stents through the LAMS has been performed to prevent recurrence.

Overall, a recent systemic review and meta-analysis of outcomes related to endoscopic ultrasound-guided cystogastrostomy for pancreatic fluid collections by Renelus et al. included seventeen studies involving 1,708 patients and reported the pooled adverse events rates for metal stents to be $14 \%$ and plastic stents to be $18 \%$ (76). Overall complications are rare and most can be managed successfully when recognized.

\section{Conclusions}

The management of pancreatic fluid collections remains an evolving field with the introduction of new and novel approaches to treatment. Most interventions are targeted towards the management of delayed complications, often four weeks after an episode of acute pancreatitis, which include pancreatic pseudocysts and WON. If there is an indication for drainage such as symptomatic collections or infected necrosis, a step-up approach to drainage should be utilized starting with EUS-guided drainage as the first line management. For the management of pseudocysts, the optimal stent for drainage remains unclear given similar clinical success rates. For the management of WON, current studies suggest the use of LAMS is likely the best approach with high technical and clinical success rates along with the ability to perform DEN. However, the potential adverse events related to the use of LAMS including increased risk of bleeding should be taken into account. The placement of double pigtail stents though a LAMS has been shown to decrease risk adverse events when compared 

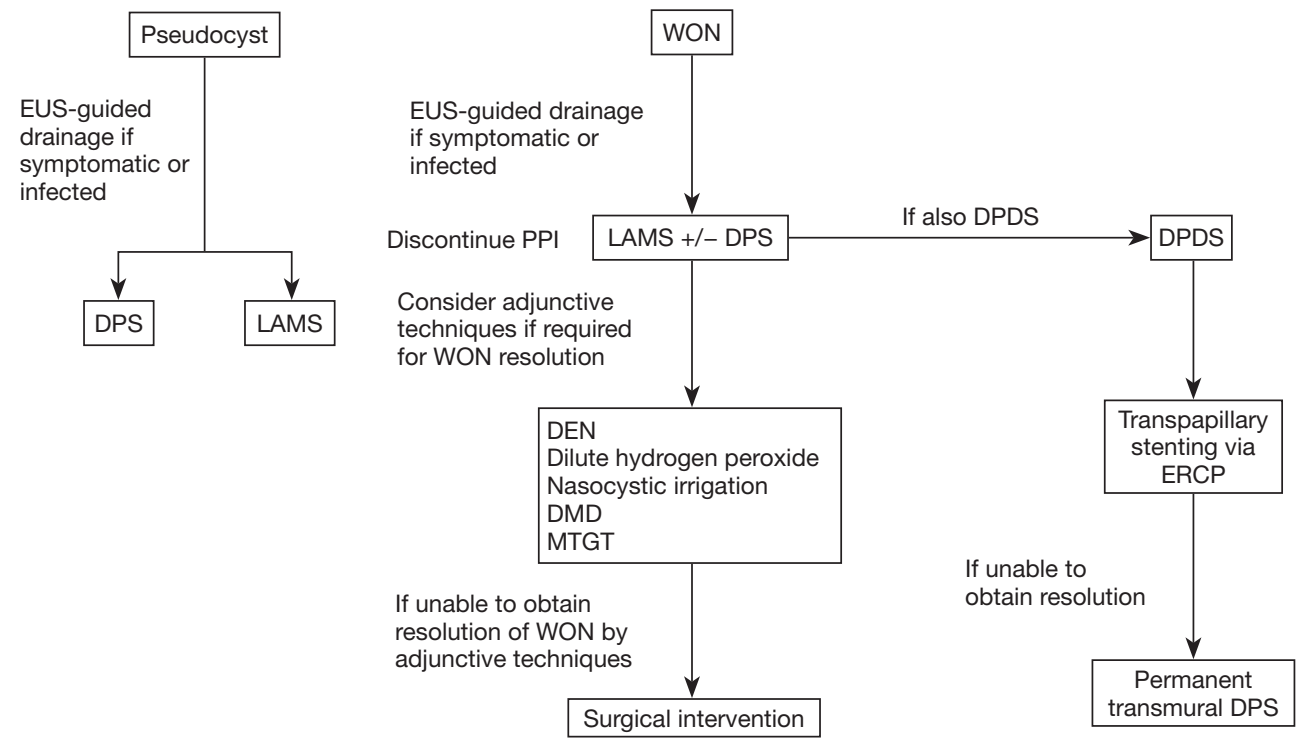

Figure 21 Flow diagram for management of pancreatic fluid collections. DPS, double pigtail plastic stent; LAMS, lumen apposing metal stent; WON, walled-off necrosis; DEN, direct endoscopic necrosectomy; DMD, dual modality drainage; MTGT, multiple transluminal gateway technique; DPDS, disconnected pancreatic duct syndrome; ERCP, endoscopic retrograde cholangiopancreatography.

to the placement of a LAMS alone (Figure 21).

\section{Acknowledgments}

Funding: None.

\section{Footnote}

Provenance and Peer Review: This article was commissioned by the Guest Editor (Amy Tyberg) for the series "Innovation in Endoscopy" published in Translational Gastroenterology and Hepatology. The article has undergone external peer review.

Conflicts of Interest: All authors have completed the ICMJE uniform disclosure form (available at https://tgh.amegroups. com/article/view/10.21037/tgh-2020-06/coif). The series "Innovation in Endoscopy" was commissioned by the editorial office without any funding or sponsorship. All authors have no other conflicts of interest to declare.

Ethical Statement: The authors are accountable for all aspects of the work in ensuring that questions related to the accuracy or integrity of any part of the work are appropriately investigated and resolved.
Open Access Statement: This is an Open Access article distributed in accordance with the Creative Commons Attribution-NonCommercial-NoDerivs 4.0 International License (CC BY-NC-ND 4.0), which permits the noncommercial replication and distribution of the article with the strict proviso that no changes or edits are made and the original work is properly cited (including links to both the formal publication through the relevant DOI and the license). See: https://creativecommons.org/ licenses/by-nc-nd/4.0/.

\section{References}

1. Tenner S, Baille J, DeWitt J, et al. American College of Gastroenterology Guideline: management of Acute Pancreatitis. Am J Gastroenterol 2013;108:1400-15.

2. Banks PA, Bollen TL, Dervenis C, et al. Classification of acute pancreatitis - 2012: revision of the Atlanta classification and definitions by international consensus. Gut 2013;62:102-11.

3. Forsmark CE, Vege SS, Wilcox CM. Acute Pancreatitis. N Engl J Med 2016;375:1972-81.

4. Lenhart DK, Balthazar EJ. MDCT of acute mild (nonnecrotizing pancreatitis): abdominal complications and fate of fluid collections. AJR Am J Roentgenol 
2008;190:643-9.

5. Balthazar EJ, Robinson DL, Megibow AJ, et al. Acute pancreatitis: value of CT in establishing prognosis. Radiology 1990;174:331-6.

6. Muthusamy VR, Chandrasekhara V, Acosta RD, et al. The role of endoscopy in the diagnosis and treatment of inflammatory pancreatic fluid collections. Gastrointest Endosc 2016;83:481.

7. Yeo CJ, Bastidas JA, Lynch-Nyhan A, et al. The natural history of pancreatic pseudocysts documented by computed tomography. Surg Gynecol Obstet 1990;170:411-7.

8. Cui ML, Kim KH, Kim HG, et al. Incidence, risk factors and clinical course of pancreatic fluid collections in acute pancreatitis. Dig Dis Sci 2014;59:1055.

9. Melman L, Azar R, Beddow K, et al. Primary and overall success rates for clinical outcomes after laparoscopic, endoscopic, and open pancreatic cystgastrostomy for pancreatic pseudocysts. Surg Endosc 2009;23:267-71.

10. Varadarajulu S, Bang JY, Sutton BS, et al. Equal efficacy of endoscopic and surgical cystogastrostomy for pancreatic pseudocyst drainage in a randomized trial. Gastroenterology 2013;145:583-90.e1.

11. van Santvoort HC, Besselink MG, Bakker OJ, et al. A step-up approach or open necrosectomy for necrotizing pancreatitis (PANTER trial). N Engl J Med 2010;362:1491-502.

12. Adams DB, Anderson MC. Percutaneous catheter drainage compared with internal drainage in the management of pancreatic pseudocyst. Ann Surg 1992;215:571-6.

13. Heider R, Meyer AA, Galanko JA, et al. Percutaneous drainage of pancreatic pseudocysts is associated with a higher failure rate than surgical treatment in unselected patients. Ann Surg 1999;229:781-7.

14. Akshintala VS, Saxena P, Zaheer A, et al. A comparative evaluation of outcomes of endoscopic versus percutaneous drainage for symptomatic pancreatic pseudocysts. Gastrointest Endosc 2014;79:921-8.

15. van Santvoort HC, Bakker OJ, Bollen TL, et al. A conservative and minimally invasive approach to necrotizing pancreatic improves outcome. Gastroenterology 2011;141:1254-63.

16. Pitchumoni CS, Agarwal N. Pancreatic pseudocysts. When and how should drainage be performed? Gastroenterol Clin North Am 1999;28:615-39.

17. Baron TH, DiMaio CJ, Wang AY, et al. American Gastroenterological Association Clinical Practice Update: management of Pancreatic Necrosis. Gastroenterology 2020;158:67-75.e1.
18. Habashi S, Draganov PV. Pancreatic pseudocyst. World J Gastroenterol 2009;15:38-47.

19. Varadarajulu S, Bang JY, Phadnis MA, et al. Endoscopic transmural drainage of peripancreatic fluid collections:outcomes and predictors of treatment success in 211 consecutive patients. J Gastrointest Surg 2011;15:2080-8.

20. Rogers BH, Cicurel NJ, Seed RW. Transgastric needle aspiration of pancreatic pseudocyst through an endoscope. Gastrointest Endosc 1975;21:133-4.

21. Kozarek RA, Brayko J, Harlan J, et al. Endoscopic drainage of pancreatic pseudocysts. Gastrointest Endosc 1985;31:322-7.

22. Lehman GA. Pseudocysts. Gastrointest Endosc 1999;49:S81-4.

23. Fabbri C, Luigiano C, Maimone A, et al. Endoscopic ultrasound-guided drainage of pancreatic fluid collections. World J Gastrointest Endosc 2012;4:479-88.

24. Tyberg A, Karia K, Moamen G, et al. Management of pancreatic fluid collections: a comprehensive review of the literature. World J Gastroenterol 2016;22:2256-70.

25. Baron TH. Endoscopic drainage of pancreatic fluid collections and pancreatic necrosis. Gastrointest Endosc Clin N Am 2003;13:743-64.

26. Park DH, Lee SS, Moon SH, et al. Endoscopic ultrasound-guided versus conventional transmural drainage for pancreatic pseudocysts: a prospective randomized trial. Endoscopy 2009;41:842-8.

27. Varadarajulu S, Christein JD, Tamhane A, et al. Prospective randomized trial comparing EUS and EGD for transmural drainage of pancreatic pseudocysts (with videos). Gastrointest Endosc 2008;68:1102-11.

28. Grimm H, Binmoeller KF, Soehendra N. Endosonography-guided drainage of a pancreatic pseudocyst. Gastrointest Endosc 1992;38:170-1.

29. Wiersema MJ. Endosonography-guided cystoduodenostomy with a therapeutic ultrasound endoscope. Gastrointest Endosc 1996;44:614-7.

30. Vilmann P, Hancke S, Pless T, et al. One-step endosonography-guided drainage of a pancreatic pseudocyst: a new technique of stent delivery through the echo endoscope. Endoscopy 1998;30:730-3.

31. Aghdassi AA, Mayerle J, Kraft M, et al. Pancreatic pseudocysts-when and how to treat? HPB (Oxford) 2006;8:432-41.

32. Holt BA, Varadarajulu S. The endoscopic management of pancreatic pseudocysts (with videos). Gastrointest Endosc 2015;81:804-12. 
33. Elmunzer BJ. Endoscopic Drainage of Pancreatic Fluid Collections. Clin Gastroenterol Hepatol 2018;16:185163.e3.

34. Sharaiha RZ, DeFilippis EM, Kedia P, et al. Metal versus plastic for pancreatic pseudocyst drainage: clinical outcomes and success. Gastrointest Endosc 2015;82:822-7.

35. Yoon SB, Lee IS, Choi MG. Metal versus plastic stents for drainage of pancreatic fluid collection: a meta-analysis. United European Gastroenterology Journal 2018;6:729-38.

36. Binmoeller KF, Shah J. A novel lumen-apposing stent for transluminal drainage of nonadherent extraintestinal fluid collections. Endoscopy 2011;43:337-42.

37. Mussetto A, Fugazza A, Fuccio L, et al. Current uses and outcomes of lumen-apposing metal stents. Ann Gastroenterol 2018;31:535-40.

38. Siddiqui AA, Adler DG, Nieto J, et al. EUS-guided drainage of peripancreatic fluid collections and necrosis by using a novel lumen-apposing stent: a large retrospective, multicenter U.S. experience (with videos). Gastrointest Endosc 2016;83:699-707.

39. Kumta NA, Tyberg A, Bhagat VH, et al. EUS-guided drainage of pancreatic fluid collections using lumen apposing metal stents: an international, multicenter experience. Dig Liver Dis 2019;51:1557-61.

40. Shah RJ, Shah JN, Waxman I, et al. Safety and efficacy of endoscopic ultrasound-guided drainage of pancreatic fluid collections with lumen-apposing covered self-expanding metal stents. Clin Gastroenterol Hepatol 2015;13:747-52.

41. Lang GD, Fritz C, Bhat T, et al. EUS-guided drainage of peripancreatic fluid collections with lumen-apposing metal stents and plastic double-pigtail stents: comparison of efficacy and adverse event rates. Gastrointest Endosc 2018;87:150-7.

42. Papachristou GI, Takahashi N, Chahal P, et al. Peroral endoscopic drainage/debridement of walled-off pancreatic necrosis. Ann Surg 2007;245:943-51.

43. Siddiqui AA, Kowalski TE, Loren DE, et al. Fully covered self-expanding metal stents versus lumen-apposing fully covered self-expanding metal stent versus plastic stents for endoscopic drainage of pancreatic walled-off necrosis: clinical outcomes and success. Gastrointest Endosc 2017;85:758-65.

44. Sharaiha RZ, Tyberg A, Khashab MA, et al. Endoscopic Therapy With Lumen-apposing Metal Stents Is Safe and Effective for Patients With Pancreatic Walled-off Necrosis. Clin Gastroenterol Hepatol 2016;14:1797-803.

45. Isenmann R, Runzi M, Kron M, et al. Prophylactic antibiotic treatment in patients with predicted severe acute pancreatitis: a placebo-controlled, double-blind trial. Gastroenterology 2004;126:997-1004.

46. Sahar N, Kozarek RA, Kanji ZS, et al. Duration of antibiotic treatment after endoscopic ultrasound-guided drainage of walled-off pancreatic necrosis not affecting outcomes. J Gastroenterol Hepatol 2018;33:1548-52.

47. Enad D, Novikov A, Nassani N, et al. Antibiotic Therapy in Infected Walled-Off Pancreatic Necrosis:Impact of Duration of Therapy on Resolution and the Development of Clostridium difficile Infection. Am J Gastroenterol 2017;112:S29.

48. Boxhoorn L, Fockens P, Besselink MG, et al. Endoscopic Management of Infected Necrotizing Pancreatitis: an Evidence-Based Approach. Curr Treat Options Gastroenterol 2018;16:333-44.

49. Powers PC, Siddiqui A, Sharaiha RZ, et al. Discontinuation of proton pump inhibitor use reduces the number of endoscopic procedures required for resolution of walled-off pancreatic necrosis. Endosc Ultrasound 2019;8:194-8.

50. Othman MO, Elhanafi S, Saadi M, et al. Extended Cystogastrostomy with Hydrogen Peroxide Irrigation Facilitates Endoscopic Pancreatic Necrosectomy. Diagn Ther Endosc 2017;2017:7145803.

51. Siddiqui AA, Easler J, Strongin A, et al. Hydrogen peroxide-assisted endoscopic necrosectomy for walled-off pancreatic necrosis: a dual center pilot experience. Dig Dis Sci 2014;59:687-90.

52. Haller G, Faltin-Traub E, Faltin D, et al. Oxygen embolism after hydrogen peroxide irrigation of a vulvar abscess. Br J Anaesth 2002;88:597-9.

53. Benali Zel A, Abdedaim H, Omari D. Massive gas embolism secondary in the use of intraoperative hydrogen peroxide:still use to lavage with this liquid? Pan Afr Med J 2013;16:124.

54. Siddiqui AA, Dewitt JM, Strongin A, et al. Outcomes of EUS-guided drainage of debris-containing pancreatic pseudocysts by using combined endoprosthesis and a nasocystic drain. Gastrointest Endosc 2013;78:589-95.

55. Rerknimitr R. Endoscopic Transmural Necrosectomy: timing, Indications, and Methods. Clin Endosc 2020;53:49-53.

56. Lakhtakia S, Basha J, Talukdar R, et al. Endoscopic "step-up approach" using a dedicated biflanged metal stent reduces the need for direct necrosectomy in walled-off necrosis (with videos). Gastrointest Endosc 2017;85:1243-52.

57. Yan L, Dargan A, Nieto J, et al. Direct endoscopic necrosectomy at the time of transmural stent placement 
results in earlier resolution of complex walled-off pancreatic necrosis: results from a large multicenter United States trial. Endosc Ultrasound 2019;8:172-9.

58. Ross A, Gluck M, Irani S, et al. Combined endoscopic and percutaneous drainage of organized pancreatic necrosis. Gastrointest Endosc 2010;71:79-84.

59. Ross AS, Irani S, Gan SI, et al. Dual-modality drainage of infected and symptomatic walled-off pancreatic necrosis: long-term clinical outcomes. Gastrointest Endosc 2014;79:929-35.

60. Varadarajulu S, Milind A, Phadnis, et al. Multiple transluminal gateway technique for EUS-guided drainage of symptomatic walled-off pancreatic necrosis. Gastrointest Endosc 2011;74:74-80.

61. Chen YI, Khashab MA, Adam V, et al. Plastic stents are more cost-effective than lumen-apposing metal stents in management of pancreatic pseudocysts. Endosc Int Open 2018;6:E780-8.

62. Chen YI, Barkun AN, Adam V, et al. Cost-effectiveness analysis comparing lumen-apposing metal stents with plastic stents in the management of pancreatic walled-off necrosis. Gastrointest Endosc 2018;88:267-76.e1.

63. Devière J, Bueso H, Baize M, et al. Complete disruption of the main pancreatic duct: endoscopic management. Gastrointest Endosc 1995;42:445-51.

64. Sandrasegaran K, Tann M, Jennings SG, et al. Disconnection of the pancreatic duct: an important but overlooked complication of severe acute pancreatitis. Radiographics 2007;27:1389-400.

65. Larsen M, Kozarek RA. Management of Disconnected Pancreatic Duct Syndrome. Curr Treat Options Gastroenterol 2016;14:348-59.

66. Fischer TD, Gutman DS, Hughes SJ, et al. Disconnected pancreatic duct syndrome: disease classification and management strategies. J Am Coll Surg 2014;219:704-12.

67. Arvanitakis M, Delhaye M, Bali MA, et al. Pancreatic-fluid collections: a randomized controlled trial regarding stent removal after endoscopic transmural drainage. Gastrointest Endosc 2007;65:609-19.

doi: $10.21037 /$ tgh-2020-06

Cite this article as: Bhakta $\mathrm{D}$, de Latour R, Khanna L. Management of pancreatic fluid collections. Transl Gastroenterol Hepatol 2022;7:17.
68. Panamonta N, Ngamruengphong S, Kijsirichareanchai K, et al. Endoscopic ultrasound-guided versus conventional transmural techniques have comparable treatment outcomes in draining pancreatic pseudocysts. Eur J Gastroenterol Hepatol 2012;24:1355-62.

69. Gambitta P, Maffioli A, Spiropoulos J, et al. Endoscopic ultrasound-guided drainage of pancreatic fluid collections: the impact of evolving experience and new technologies in the diagnosis and treatment over the last two decades. Hepatobiliary Pancreat Dis Int 2020;19:68-73.

70. Rana SS, Shah J, Kang M, et al. Complications of endoscopic ultrasound-guided transmural drainage of pancreatic fluid collections and their management. Ann Gastroenterol 2019;32:441-50.

71. Lakhtakia S. Complications of diagnostic and therapeutic Endoscopic Ultrasound. Best Pract Res Clin Gastroenterol 2016;30:807-23.

72. Brimhall B, Han S, Tatman PD, et al. Increasing Incidence of Pseudoaneurysm Bleeding With Lumen-Apposing Metal Stents Compared to Double-Pigtail Plastic Stents in Patients with Peripancreatic Fluid Collections. Clin Gastroenterol Hepatol 2018;16:1521-8.

73. Varadarajulu S, Christein JD, Wilcox CM. Frequency of complications during EUS-guided drainage of pancreatic fluid collections in 148 consecutive patients. J Gastroenterol Hepatol 2011;26:1504-8.

74. Aburajab M, Smith Z, Khan A, et al. Safety and efficacy of lumen-apposing metal stents with and without simultaneous double-pigtail stents for draining pancreatic pseudocyst. Gastrointest Endosc 2018;87:1248-55.

75. Penn DE, Draganov PV, Wagh MS, et al. Prospective evaluation of the use of fully covered self-expanding metal stents for EUS-guided transmural drainage of pancreatic pseudocysts. Gastrointest Endosc 2012;76:679-84.

76. Renelus BD, Jamorabo DS, Gurm HK, et al. Comparative outcomes of endoscopic ultrasound-guided cystogastrostomy for peripancreatic fluid collections: a systemic review and meta-analysis. Ther Adv Gastrointest Endosc 2019;12:263177451984340. 